\title{
Identification of a five-miRNA signature predicting survival in cutaneous melanoma cancer patients
}

\author{
Tao Lu ${ }^{1,2}$, Shuang Chen ${ }^{1}$, Le Qu ${ }^{1}$, Yu lin Wang ${ }^{1}$, Hong- duo Chen ${ }^{1}$, Chun di He ${ }^{\text {Corresp. }{ }^{1}}$ \\ 1 Department of Dermatology, No.1 Hospital of China Medical University, shenyang, Liao Ning, China \\ 2 Department of Dermatology, Affiliated Hospital of Chifeng University, chifeng, Inner Mongolia, China \\ Corresponding Author: Chun di He \\ Email address: cdhe@cmu.edu.cn
}

Background. Cutaneous melanoma (CM) is the deadliest form of skin cancer. Numerous studies have revealed that microRNAs (miRNAs) are expressed abnormally in melanoma tissues. Our work aimed to assess multiple miRNAs using bioinformatic analysis in order to predict the prognoses of cutaneous melanoma patients. Methods. The microarray dataset GSE35579 was downloaded from the Gene Expression Omnibus (GEO) database to detect the differential expression of miRNAs (DEMs), including 41 melanoma (primary and metastatic) tissues and 11 benign nevi. Clinical information and miRNA sequencing data of cutaneous melanoma tissues were downloaded from the Cancer Genome Atlas database (TCGA) to assess the prognostic values of DEMs. Additionally, the target genes of DEMs were anticipated using miRanda, miRmap, TargetScan, and PicTar. Finally, functional analysis was performed using selected target genes on the Annotation, Visualization and Integrated Discovery (DAVID) website. Results. After performing bioinformatic analysis, a total of 185 DEMs were identified: 80 upregulated miRNAs and 105 downregulated miRNAs. A five-miRNA (miR-25, miR-204, miR-211, miR-510, miR-513c) signature was discovered to be a potential significant prognostic biomarker of cutaneous melanoma when using the Kaplan-Meier survival method $(P=0.001)$. Univariate and multivariate Cox regression analyses showed that the five-miRNA signature could be an independent prognostic marker ( $H R=0.605, P=0.006)$ in cutaneous melanoma patients. Biological pathway analysis indicated that the target genes may be involved in PI3K-Akt pathways, ubiquitin-mediated proteolysis, and focal adhesion. Conclusion. The identified five-miRNA signature may serve as a prognostic biomarker, or as a potential therapeutic target, in cutaneous melanoma patients . 
1

2 Identification of a five-miRNA signature predicting survival in

3 cutaneous melanoma cancer patients

4

5

6

7 Tao $\mathrm{Lu}^{1,2}$, Shuang Chen ${ }^{1}$, Le Qu ${ }^{1}$, Yulin Wang ${ }^{1}$, Hong-duo Chen ${ }^{1}$, Chundi $\mathrm{He}^{1}$

8

$9 \quad{ }^{1}$ Department of Dermatology, No.1 Hospital of China Medical University, Shenyang, Liao Ning, China

$10{ }^{2}$ Department of Dermatology, Affiliated Hospital of Chifeng University, Chifeng, Inner Mongolia,

11 China

12

13

14

15

Corresponding Author:

Chundi $\mathrm{He}^{1}$

16 Shenyang, Liaoning, China

17 Email address: cdhe@cmu.edu.cn

18

19

20

21

22

23

24

25

26

27

28

29

30

31

32

33

34

35

36

37

38

39

40

41

42

43

44 
45 Abstract

46 Background. Cutaneous melanoma $(\mathrm{CM})$ is the deadliest form of skin cancer. Numerous studies 47 have revealed that microRNAs (miRNAs) are expressed abnormally in melanoma tissues. Our 48 work aimed to assess multiple miRNAs using bioinformatic analysis in order to predict the 49 prognoses of cutaneous melanoma patients.

50 Methods. The microarray dataset GSE35579 was downloaded from the Gene Expression 51 Omnibus (GEO) database to detect the differential expression of miRNAs (DEMs), including 41 52 melanoma (primary and metastatic) tissues and 11 benign nevi. Clinical information and miRNA 53 sequencing data of cutaneous melanoma tissues were downloaded from the Cancer Genome 54 Atlas database (TCGA) to assess the prognostic values of DEMs. Additionally, the target genes 55 of DEMs were anticipated using miRanda, miRmap, TargetScan, and PicTar. Finally, functional 56 analysis was performed using selected target genes on the Annotation, Visualization and 57 Integrated Discovery (DAVID) website.

58 Results. After performing bioinformatic analysis, a total of 185 DEMs were identified: 80 59 60 upregulated miRNAs and 105 downregulated miRNAs. A five-miRNA (miR-25, miR-204, miR211, miR-510, miR-513c) signature was discovered to be a potential significant prognostic biomarker of cutaneous melanoma when using the Kaplan-Meier survival method $(P=0.001)$. Univariate and multivariate Cox regression analyses showed that the five-miRNA signature could be an independent prognostic marker $(\mathrm{HR}=0.605, P=0.006)$ in cutaneous melanoma patients. Biological pathway analysis indicated that the target genes may be involved in PI3KAkt pathways, ubiquitin-mediated proteolysis, and focal adhesion.

Conclusion. The identified five-miRNA signature may serve as a prognostic biomarker, or as a

68

69

70

71

72

73

74

75 76

77

78

79

80

81

82

83

84

8

0
potential therapeutic target, in cutaneous melanoma patients.

\section{Introduction}

Melanoma is the result of the malignant transformation of melanocytes. It accounts for approximately only 5\% of all skin malignancies, but is thought to be the most invasive and lethal form (Dimitriou et al. 2018). When compared with non-melanoma skin cancer, melanoma has higher invasiveness and a worse prognosis, and its incidence has increased significantly in recent years (Ross et al. 2018). The histopathological features of melanoma are not as distinguishing as its molecular heterogeneity, and its formation is based on the continuous alteration of specific genes and pathways that control metabolism or regulate key cellular functions (Palmieri et al. 2018). Although new treatments for melanoma are constantly being developed, their effectiveness is still unsatisfactory. If metastasis occurs, the results could be life-threatening, prompting clinicians to pursue new predictive markers and targeted therapeutic genes (Falzone et al. 2018; Leonardi et al. 2018; Perera et al. 2013). 
85

86

87

88

89

90

91

92

93

94

95

96

97

98

99

100

101

102

103

104

105

106

107

108

109

110

111

112

113

114

115

116

117

118

119

120

121

122

123

124

MicroRNAs (miRNAs) are small single-stranded non-coding RNAs with oncogenic or tumorsuppressive roles, consisting of 20-26 nucleotides. There is growing evidence that miRNAs play key roles in multiple developmental stages of human cancers, including cutaneous melanoma (Gulyaeva \& Kushlinskiy 2016). These molecules can affect gene transcription by complementing the promoter region of a particular gene or by directly regulating the activity of a gene (Piletic \& Kunej 2016). miRNAs can even be released into the bloodstream by a tumor and can be detected in melanoma cells. Dysregulated miRNAs can also be used as survival markers in cutaneous melanoma patients (Riefolo et al. 2019), as seen in the signature of 18 miRNAs identified by Segura MF et al. (Segura et al. 2010) and the miRNAs identified by Caramuta, $\mathrm{S}$ et al. (Caramuta et al. 2010).

With the development of sequencing technology and various omics (genomics, transcriptomics, proteomics, etc.), a large amount of biological data have been acquired, leading to the development of bioinformatics to mine, utilize and integrate these data (Manzoni et al. 2018). Bioinformatics can be defined as the practical discipline of applying informatics technology (including applied mathematics, computer science and statistics) to understand and process biological tissue information related to macromolecules on a large scale (Luscombe et al. 2001). It has been applied in various fields of biological research, such as in the identification or diagnosis of disease biomarkers (Shergalis et al. 2018), individualized treatment of cancer, the preparation of tumor vaccines (Hu et al. 2018), among others. Various large public bioinformatics databases have been developed, such as the Gene Expression Omnibus (GEO, https://www.ncbi.nlm.nih.gov/geo/) database, which is a functional genomics data repository that help users download experiments and curate gene expression profiles (Barrett et al. 2013), and the Cancer Genome Atlas (TCGA, https://portal.gdc.cancer.gov/), which is the most useful tumor genomics program with at least 30 cancer types included (Chandran et al. 2016). These two databases play a wide range of roles in the research of cancers including melanoma. For example, the data provided by GEO are used in the screening of melanoma prognostic factors (Hu et al. 2019; Xin et al. 2019). Robertson et al. conducted an in-depth analysis of UM (uveal melanoma) samples from TCGA project in order to gain a deeper understanding of the biological processes of UM tumors with distinct prognoses (Robertson et al. 2017). Even anti-tumor drugs in melanoma patients with or without anti-PD-1 treatment have been analyzed using the GEO and TCGA databases (Wu et al. 2019).

Previous studies have shown that multiple miRNAs can be used as diagnostic and prognostic markers, but the number of cases is relatively small with inconsistent results (Jayawardana et al. 2016; Ross et al. 2018). In our study, we screened microarray data from GEO, then downloaded the clinical information and expression profiles of cutaneous melanoma patients from TCGA. Our aim was to use bioinformatics methods on a large sample from TCGA database, evaluate the prognostic value of the differential expression of miRNAs (DEMs) by analyzing the highthroughput sequencing data, and establish a five-miRNA predictive signature of patient survival. 
125 Materials \& Methods

126 Acquisition of a microarray data source and DEMs

127 Variations in sample collection, storage, batch testing and detection platform methods can lead to

128 data deviation, and so we could not simply directly combine different datasets. When selecting

129 datasets, the inclusion criteria were: 1) datasets including more than 40 samples; 2) datasets with

130 tumor tissue samples; and 3) datasets containing melanoma (including primary and metastatic

131 melanoma) and pigmented nevi tissue simultaneously. Ultimately, GSE35579 (cutaneous

132 melanoma $=41$, nevus $=11$ ) was the one that met our requirements. After microarray data were

133 downloaded from the GEO of the National Center for Biotechnology Information (NCBI), we

134 preprocessed the miRNA expression data using the quantile normalized method, then identified

135 DEMs between melanoma and benign nevi. The "limma" package in software R (version 3.5.2),

136 which can be operated flexibly offline, was selected to process the differential expression data.

$137 P<0.05$ was selected as the statistically significant cut-off criterion.

138

139

140

141

\section{Identification of the relationship between DEMs and overall survival (OS) in melanoma} patients

142

DEMs obtained from the GEO database were matched in TCGA's database for further analysis

of their relationship to patient prognosis. After removing patients without completed clinical information and with an OS (overall survival) time $<1$ month, the remaining 428 patients were divided into high - risk and low - risk groups according to the median score of DEM expression level. We used 120 months as the end of our observation time, and patients with a survival period of more than 120 months were considered survivors. The DEM expression profiles acquired from TCGA, after being $\log 2$ transformed, were assessed with the Kaplan-Meier method and a log-rank test to preliminarily identify the miRNAs that were associated with patient survival. $P<0.05$ was considered to indicate statistically significant differences. Considering that multiple miRNAs have more reliable predictive effects, we used different combinations of several prognosis-related miRNAs to calculate the risk score for each melanoma patient in accordance with a high or low level of expression. Using this method, we classified the patients into two groups, high and low score groups, further using Kaplan-Meier analysis to assess these miRNA combinations. To make the experiment more objective, we only selected a meaningful combination of DEMs for follow-up study. The Kaplan-Meier results were visualized by the GraphPad Prism 5.0. Finally, univariate and multivariate Cox regression analyses were conducted to verify the prognostic role of the screened DEM signature.

\section{Prediction of the DEM signature's target genes}

161 TargetScan (http://www.targetscan.org/), miRDB (http://www.mirdb.org/), DIANA

162 (http://www.microrna.gr/microTCDS), and miRmap (https://mirmap.ezlab.org/app/) were used 163 to predict these candidate target genes. The FunRich (Functional enrichment analysis 
164 (http://www.funrich.org/)) tool was used to intersect the results of the four prediction tools for

165

166

167

168

169

170

171

172

173

174

175

176

177

178

179

180

181

182

183

184

185

186

187

188

189

190

191

192

193

194

195

196

197

198

199

200

201

202

203

further research.

\section{Analysis of functions and pathways of target genes}

GO term and KEGG pathway analysis was conducted on the overlapping terms in the Database for Annotation, Visualization and Integrated Discovery (DAVID, https://david.ncifcrf.gov/home.jsp) websites, providing a comprehensive set of functional annotation tools to help determine the biological meaning of the genes. The results were visualized by the R "ggplot2" package. A $P$-value $<0.05$ was set as the cut-o $\square$ criterion.

\section{Statistical analysis}

To compare the miRNA expression data between melanomas and nevi, we used unpaired $t$-tests. The relationship between expression data and the melanoma patients' clinical information was assessed with chi-square and $t$-tests. Kaplan-Meier survival analysis and univariate/multivariate Cox proportional hazard regression analyses were performed using IBM SPSS Statistics 25.0 to assess each DEM and miRNA signature prognostic function. A $P$-value $<0.05$ was considered statistically significant.

\section{Results}

\section{DEM identification and construction of a five-miRNA signature}

We first acquired 185 (80 upregulated and 105 downregulated) differentially expressed miRNAs between melanomas (primary and metastatic) and benign nevi from the miRNA dataset GSE35579, according to the standard of $P<0.05$. To make the results more intuitive, we used volcano maps (Fig. 1) to show these DEMs. To find out whether differential miRNAs could distinguish a cancer sample from a nevus sample, we selected the top 100 miRNAs with the most obvious differences in expression to perform a hierarchic cluster heat map based on Euclidean distance (as shown in Fig. 2), and the results were acceptable.

DEMs were matched in TCGA, and combined with the clinical information of melanoma patients (shown in Table 1). DEMs that could not be found in TCGA were excluded, and each miRNA was analyzed to determine whether it was related to the prognoses. According to our statistical analysis, there were eight genes (miR-25, miR-100, miR-204, miR-211, miR-19b, miR-510, miR-511, miR-513c) closely related to the prognoses of the patients.

We integrated the expression of these eight miRNAs and applied different combinations calculating the risk score for each patient (the details of which can be found in the Methods section), and we found a very obvious prognostic significance when five of the miRNAs (miR25, miR-204, miR-211, miR-510, miR-513c) were combined. Among these miRNAs, miR-204 correlated positively with prognosis, while miR-25, miR-211, miR-510, and miR-513c correlated negatively with prognosis. These details are listed in Table 2 . We then established a fivemiRNA-based prognostic model. The prognostic characteristics of these five miRNAs are shown in Figure 2 (Figs. 3A-3E). According to the median risk score, 428 patients were divided into a 
204 high-risk group $(\mathrm{n}=222)$ and a low-risk group $(\mathrm{n}=206)$. Survival analysis was performed using 205 the Kaplan-Meier method with the log-rank test. The results showed that the survival rate of the 206 high-risk group was significantly lower than that of the low-risk group ( $\mathrm{P}=0.001$, Fig. 3F). To 207 explore whether these five miRNAs were related to clinical features, we conducted correlation 208 analysis and found that, except for miR-25, these miRNAs might be related to $\mathrm{T}$ stage and 209 Breslow depth value (see Table 3 for details).

210 Univariate and multivariate Cox regression analyses were used to test the effects of the five 211 miRNA features (high-risk and low-risk) combined with the clinical features of melanoma 212 patients (including age, $\mathrm{T}$ stage, $\mathrm{N}$ stage, $\mathrm{M}$ stage, and clinical stage) on OS (overall survival).

213 Univariate analysis showed that $\mathrm{T}$ stage $(\mathrm{HR}=0.443, P<0.000)$, $\mathrm{N}$ stage $(\mathrm{HR}=0.517, P$ $214<0.000)$, clinical stage $(\mathrm{HR}=0.543, P<0.000)$, age at diagnosis $(\mathrm{HR}=1.563, P=0.003)$, 215 Breslow depth value $(\mathrm{HR}=0.370, P<0.000)$ and the five-miRNA characteristics $(\mathrm{HR}=0.613$, $216 P=0.001)$ were associated with OS in melanoma patients. In the multivariate analysis, the five217 miRNA characteristics $(\mathrm{HR}=0.605, P=0.006), \mathrm{N}$ stage $(\mathrm{HR}=0.246, P=0.008)$ and Breslow 218 depth value (HR $=0.509, P=0.011)$ were all shown to be independent prognostic factors for 219 patients with cutaneous melanoma (Table 4).

220

221

222

223

224

225

226

227

228

229

230

231

232

233

234

235

236

237

238

239

240

241

242

243

\section{GO and KEGG pathway analysis of target genes of the five-miRNA signature}

Using TargetScan, miRDB, DIANA, and miRmap, we predicted five miRNA target genes (miR25, miR-204, miR-211, miR-510, and miR-513c). The four prediction tools' intersecting genes were visualized using the FunRich tool (Figs. 4A-4E). A total of 367 (228 miR-25, $28 \mathrm{miR}-204$, $31 \mathrm{miR}-211,77 \mathrm{miR}-510,37 \mathrm{miR}-513 \mathrm{c}$, and deleted duplicate values) overlapping genes were entered into DAVID, and assessed by GO and KEGG pathway analyses. The biological process (BP) analysis results showed that the genes were concentrated in the transcription regulation, angiogenesis, protein phosphorylation and ubiquitination (Fig. 5A). Cellular component (CC) analysis showed that these genes were concentrated in the cytoplasm, nucleus, focal adhesion and cell-cell adherens junctions (Fig. 5B). Molecular function (MF) analysis showed that genes were concentrated in protein binding and ubiquitin-protein transferase activity (Fig. 5C). KEGG pathway analysis showed that these genes were concentrated in the PI3K-Akt signaling pathway, ubiquitin-mediated proteolysis, and focal adhesion pathway (Fig. 5D).

\section{Discussion}

The melanocyte pedigree is derived from the neural ridge, originating in the neural tube, and these cells migrate to specific locations in the skin , hair follicle and other parts of the body during embryonic development. In patients with vitiligo, the pigment "island" appears first in a location around the hair follicles after UVB treatment, which suggests that melanocytes have stem cell properties. These characteristics may contribute to the melanoma-derived invasion (Richard L. Mort 2015). Caucasian populations have had a stable CM mortality rate since the 1990s, while the age-standardized mortality rate of cutaneous melanoma patients in East Asian populations has significantly increased over the past six decades (Chen \& Jin 2016). As the aging population grows, the incidence of melanoma is predicted to also increase (Karimkhani et al. 
244 2017). Early detection and initial care are still crucial for treatment (Schadendorf et al. 2018).

245 Recent studies have shown that epigenetic mechanisms play a very complex role in the

246 development and progression of melanoma, including its methylation, chromosomal changes and

247 remodeling, and regulation of the active function of various non-coding RNAs (Sarkar et al.

248 2015). Research on microRNAs is more developed compared to that of other non-coding RNAs,

249 and these molecules play a significant role in nearly every biological process in nevi and

250 melanomas, including proliferation, invasion, and apoptosis. Because of their chemical stability,

251 these molecules can resist the degradation of RNase and can distinguish between different types

252 of cancers, specifically those that can be secreted into the serum by tumor cells. Therefore, these

253 molecules can be used to predict the prognosis and to perform the initial diagnosis in melanoma

254 patients (Ross et al. 2018). Previous studies have explored the relationship between miRNAs and

255 the prognoses of melanoma patients, but these studies were usually small sample studies without

256 uniform results, that only looked at the primary melanoma or metastatic stage of the tumor, and

257 only focused on single miRNAs (Galasso et al. 2018; Jayawardana et al. 2016; Sanchez-Sendra

258 et al. 2018). TCGA's database contains an abundance of cancer information, making access to

259 cancer expression profile data easy and cost-effective. However, unlike for other cancers,

260 TCGA's database only contains skin melanoma samples without normal control tissue nor nevi

261 tissue information, and we were unable to obtain differentially expressed miRNAs. Thus, we

262 obtained the DEMs from the GEO database, performed prognostic analysis on the DEMs with

263 expression profiles and clinical information sourced from TCGA's database, and gained eight

264 prognosis-associated miRNAs. Considering that the main purpose of our experiment was to

265 create a multi-gene-based reliable prognostic signature, and the different combinations of these

266 miRNAs were not all meaningful, we will only discuss the five-miRNA signature that can be

267 used as a prognostic factor to make our results more clear and purposeful. Through additional

268 analysis, we established a five-miRNA (miR-25, miR-204, miR-211, miR-510, miR-513c)

269 signature to make the results more reliable. This five-miRNA based signature associated with the

270 prognosis of cutaneous malignant melanoma will provide a theoretical basis for later studies, and

271 can be used to non-invasively predict clinical prognoses in melanoma patients.

272 We used previous miRNA studies to verify the reliability of our results. In our study, miRNA-25

273 was the sole upregulated microRNA of the five miRNAs. Zhu et al. found that miRNA-25 can be

274 secreted into serum and can be used as a marker for the early diagnosis of gastric cancer (Zhu et

275 al. 2014). Kim et al. found that miRNA-25 directly regulates P57 (a tumor suppressor gene), and

276 the abnormal expression of this miRNA in gastric cancer patients can advance cancer cells from

277 G1 to S phase (Kim et al. 2009). Liu et al. tested the serum of patients with pancreatic cancer and

278 found that miRNA-25 levels were considerably higher than that of the normal control group,

279 indicating that miRNA-25 can be used in the prognosis of pancreatic cancer (Liu et al. 2012).

280 Zoni et al. observed that miR-25 is a key regulator of human prostate cancer invasiveness, and

281 that it interacts directly with $\alpha(v)$ - and $\alpha(6)$ - integrins. Interestingly, Zoni et al. also found that

$282 \mathrm{miR}-25$ was a tumor suppressor in highly aggressive prostate cancer (Zoni et al. 2015). Huo et al.

283 found that the expression of miR-25 increased in melanoma tissue and melanocyte cell lines, and 
284 promoted melanoma cell proliferation and invasion, in part, by targeting Dickkopf-associated

285

286

287

288

289

290

291

292

293

294

295

296

297

298

299

300

301

302

303

304

305

306

307

308

309

310

311

312

313

314

315

316

317

318

319

320

321

322 protein 3 (DKK3) (Huo et al. 2016). This result is consistent with the poorer prognosis in melanoma patients with increased miRNA-25 expression. In our experiments, miRNA-204 was expressed at low levels in melanoma cells, and K-M survival analysis showed that the higher the expression, the longer the OS time. This finding is consistent with previous studies, such as Xin Chen et al.'s mechanistic study on the LINC01234-miR-204-5p-CBFB axis in gastric cancer patients where miR-204 was found to have low expression in gastric cancer tissues. In a gastric cancer cell miR-204 over exposure assay, miR-204 was found to inhibit the proliferation of cancer cells and to induce apoptosis and cell cycle arrest in G1 -G0 phase, and survival analysis showed that patients with higher miR-204 levels had a better prognosis (Chen et al. 2018). In studies of colorectal cancer, nasopharyngeal carcinoma, and melanoma, miRNA-204 was suggested to have an inhibitory effect on cancer cells and to possibly be associated with cancer cell resistance or anti-radiation mechanisms (Bian et al. 2016; Diaz-Martinez et al. 2018; Lu et al. 2016). Marco et al. suggested that the low expression or loss of miR-204 play a key role in the progression of melanoma. In this study, miR-204 was associated with a better prognosis in cutaneous melanoma patients (Galasso et al. 2018). Previously published studies and data from existing miRNA databases indicate that miR-204-5p and miR-211-5p share some common targets, and, as a matter of fact, miR-204 and miR-211 have very similar nuclear targets. The nucleotide sequence has only two different nucleotides in the entire sequence and in the same seed region, which may be why these molecules share some common targets. In preceding studies, these miRNAs acted as tumor suppressors in melanoma and inhibited cell invasion (Diaz-Martinez et al. 2018; Levy et al. 2010). The most important function of miR-211 is the direct or indirect targeting of many other genes that may affect melanoma invasiveness and adhesion (Bell et al. 2014). In our study, both miR-204 and miR-211 were down regulated in melanoma tissues, but miR-204 was positively associated with tumor progression , miR-211 showed the opposite results. This result may be due to the small sample size of the GEO data set we selected. The reason for this situation needs further exploration. Early research of miR-510 did not examine its relationship with cancer, only its aberrant expression in irritable bowel syndrome (Kapeller et al. 2008). Researchers later discovered its relationship to cancer; for example, Patnaik et al. found that miR-510 can predict the survival of patients with local stage I non-small cell lung cancer after surgical resection (Patnaik et al. 2010). miR-510 also plays a role in promoting tumor growth and invasion in breast cancer (Guo et al. 2013). In our study, we found that the higher the expression of miR-510, the poorer the prognoses of melanoma patients. Mairinger et al. proposed that the expression of miR-513c in pulmonary neuroendocrine tumors was involved in tumor grade, and Wang et al. studied African-American patients with prostate cancer and acquired similar results (Mairinger et al. 2014; Wang et al. 2015). Previous studies also included miR-513c in the establishment of a nine-miRNA based uveal melanoma prognostic model (Xin et al. 2019). However, we missed including a related study on the mechanism of action of miR-510 and miR-513c in cutaneous melanoma.

Peer) reviewing PDF | (2019:06:38582:1:2:NEW 30 Aug 2019) 
323 To further verify the active mechanisms of these five miRNAs, we performed miRNA target

324

325

326

327

328

329

330

331

332

333

334

335

336

337

338

339

340

341

342

343

344

345

346

347

348

349

350

351

352

353

354

355

356

357

358

359

360

361

362

gene predictions and found a total of 367 overlapping target genes. Interestingly, 222 of them were target genes derived from miR-25 (mainly enriched in the PI3K-Akt signaling pathway), 77 were target genes derived from miR-510 (mainly enriched in ubiquitin-mediated proteolysis), and the few remaining genes were target genes of other miRNAs. KEGG pathway analysis revealed that these target genes were mainly involved in the PI3K-Akt pathway, ubiquitinmediated proteolysis, and cell adhesion. The most abundant genes, including PHLPP2, SGK3, CREB5, COL5A3, PTEN, ITGA5, ITGAV, COL27A1, CREB3L2, COL1A2, PPP2R5E, PIK3AP1, GNG2, and PIK3R3, were enriched in the PI3K-Akt pathway. The PI3K-Akt pathway (phosphoinositide 3-kinase-RAC-alpha serine/threonine-protein kinase) is involved in a variety of cellular processes in both normal cells and cancer cells, including cell survival, metabolism, transmigration, and proliferation (Schadendorf et al. 2018). For example, abnormal PI3K-AktmTOR signaling is one of the most common dysfunctions present in human cancers (Janku et al. 2018). The use of PI3K-Akt as a target in the treatment of cancer has been extensively researched (Hamzehzadeh et al. 2018). Phosphatase and tensin homolog (PTEN), a tumor suppressor gene, has been the focus of many studies. PI3K-Akt-PTEN signaling has been confirmed in previous studies of breast cancer and prostate cancer (Jamaspishvili et al. 2018; Schadendorf et al. 2018; Yang et al. 2016). In cutaneous melanoma, PTEN is downregulated, and this type of PTEN loss can increase T cell-mediated immunotherapy resistance (Peng et al. 2016). In our study, we showed that miR-25 may promote the development of cutaneous melanoma by downregulating the expression of PTEN, thus affecting the prognoses of melanoma patients. Feng et al. increased the sensitivity of hepatoma stem cells to TRAIL (Tumor necrosis factor (TNF) -related apoptosis-inducing ligand), reducing apoptosis by knocking out miR-25. This effect is also achieved through the PTEN/PI3K/Akt signal pathway (Feng et al. 2016). The adhesion-related genes obtained by KEGG analysis included ACTB, ITGA5, ITGAV, COL27A1, COL1A2, RAP1B, SHC1, COL5A3, PIK3R3, PPP1CC, and PTEN, and we found that most of these genes were also involved in the PI3K signaling pathway. Degradation of the basement membrane and the extracellular matrix (ECM) is critical for the invasion and metastasis of malignant cells. ECM ligands not only control cell adhesion, migration, and actin cytoskeleton structure through signaling pathways, but they also control anchorage dependence, a key group of survival mechanisms (Ciolczyk-Wierzbicka \& Laidler 2018; Multhaupt et al. 2016). While COL27A1, COL1A2, and COL5A3 are encoded ECM components, experiments have found that the upregulation of COL1A2 in cancer can serve as a molecular basis for metastasis development (Lin et al. 2016). Integrins are the major celladhesive receptor; are key components of signaling molecules, mechanical transducers, and cellular migration mechanisms; and are involved in many aspects ranging from primary tumor to metastatic cancer progression (Hamidi \& Ivaska 2018) Integrin-alpha-5 (ITGA5) and integrinalpha-V (ITGAV) are members of the integrin receptor gene family, closely related to the regulation of cancer growth and metastasis (Chernaya et al. 2018; Morandi et al. 2016). Ubiquitination is a widespread post-transcriptional modification, a selective marker that binds to

Peer) reviewing PDF | (2019:06:38582:1:2:NEW 30 Aug 2019) 
363 protein aggregates and dysfunctional organelles, thereby promoting autophagy-dependent

364 degradation. Autophagy can promote the growth of tumor cells by maintaining arginine-serine

365 circulation (Grumati \& Dikic 2018; Poillet-Perez et al. 2018). Yang et al. showed that ubiquitin-

366 mediated proteolysis by bioinformatics analysis may have potential as a prognostic and

367 predictive marker for survival in patients with uveal melanoma (Yang et al. 2019).

368 In summary, the five screened miRNAs and their target genes were closely related to the

369 occurrence and development of tumors, and the results proved reliable. Our established five-

370 miRNA signature theoretically predicted the survival of melanoma patients, but further

371 experiments are needed to determine the mode of action and mechanism of these miRNAs, and

372 whether they can be used in a non-invasive diagnostic method.

373

374

\section{Conclusion}

376 The five screened miRNAs and their target genes were closely related to the occurrence and

377 development of tumors, and the results proved reliable. The identified five-miRNA signature

378 may serve as a prognostic biomarker, or even as a potential therapeutic target, in cutaneous

379 melanoma patients.

380

381

382

383

384

385

386

miRNAs microRNAs

387 DEMs the differential expression of miRNAs

388 GEO Gene Expression Omnibus

389 TCGA The Cancer Genome Atlas

390 UM Uveal Melanoma

391 DAVID Annotation, Visualization and Integrated Discovery

392 GO Gene Ontology

393 OS overall survival

394 HR hazard ratio

395 PI3K-Akt phosphoinositide 3-kinase-RAC-alpha serine/threonine-protein kinase

396 CM cutaneous melanoma

$397 \quad$ ECM extracellular matrix

398

Acknowledgements

400

We thank Chen Zhang, Yaling Li, and Xiaoqing Jian for their support over the past years. 
404

405

406

407

408

409

410

411

412

413

414

415

416

417

418

419

420

421

422

423

424

425

426

427

428

429

430

431

432

433

434

435

436

437

438

439

440

441

442

443

444

445

446

447

448

449

450

\section{References}

Barrett T, Wilhite SE, Ledoux P, Evangelista C, Kim IF, Tomashevsky M, Marshall KA, Phillippy $\mathrm{KH}$, Sherman PM, Holko M, Yefanov A, Lee H, Zhang N, Robertson CL, Serova N, Davis S, and Soboleva A. 2013. NCBI GEO: archive for functional genomics data sets-update. Nucleic Acids Res 41:D991-995. 10.1093/nar/gks1193

Bell RE, Khaled M, Netanely D, Schubert S, Golan T, Buxbaum A, Janas MM, Postolsky B, Goldberg MS, Shamir R, and Levy C. 2014. Transcription Factor/microRNA Axis Blocks Melanoma Invasion Program by miR-211 Targeting NUAK1. Journal of Investigative Dermatology 134:441-451. 10.1038/jid.2013.340

Bian Z, Jin L, Zhang J, Yin Y, Quan C, Hu Y, Feng Y, Liu H, Fei B, Mao Y, Zhou L, Qi X, Huang S, Hua D, Xing C, and Huang Z. 2016. LncRNA-UCA1 enhances cell proliferation and 5-fluorouracil resistance in colorectal cancer by inhibiting miR-204-5p. Sci Rep 6. 10.1038/srep23892

Caramuta S, Egyhazi S, Rodolfo M, Witten D, Hansson J, Larsson C, and Lui WO. 2010. MicroRNA expression profiles associated with mutational status and survival in malignant melanoma. J Invest Dermatol 130:2062-2070. 10.1038/jid.2010.63

Chandran UR, Medvedeva OP, Barmada MM, Blood PD, Chakka A, Luthra S, Ferreira A, Wong KF, Lee AV, Zhang Z, Budden R, Scott JR, Berndt A, Berg JM, and Jacobson RS. 2016. TCGA Expedition: A Data Acquisition and Management System for TCGA Data. PLoS One 11:e0165395. 10.1371/journal.pone.0165395

Chen L, and Jin S. 2016. Trends in mortality rates of cutaneous melanoma in East Asian populations. PeerJ 4:e2809. 10.7717/peerj.2809

Chen X, Chen Z, Yu S, Nie F, Yan S, Ma P, Chen Q, Wei C, Fu H, Xu T, Ren S, Sun M, and Wang Z. 2018. Long Noncoding RNA LINC01234 Functions as a Competing Endogenous RNA to Regulate CBFB Expression by Sponging miR-204-5p in Gastric Cancer. Clin Cancer Res 24:2002-2014. 10.1158/1078-0432.CCR-17-2376

Chernaya G, Mikhno N, Khabalova T, Svyatchenko S, Mostovich L, Shevchenko S, and Gulyaeva L. 2018. The expression profile of integrin receptors and osteopontin in thyroid malignancies varies depending on the tumor progression rate and presence of BRAF V600E mutation. Surg Oncol 27:702-708. 10.1016/j.suronc.2018.09.007

Ciolczyk-Wierzbicka D, and Laidler P. 2018. The inhibition of invasion of human melanoma cells through N-cadherin knock-down. Med Oncol 35:42. 10.1007/s12032-018-1104-9

Diaz-Martinez M, Benito-Jardon L, Alonso L, Koetz-Ploch L, Hernando E, and Teixido J. 2018. miR-204-5p and miR-211-5p Contribute to BRAF Inhibitor Resistance in Melanoma. Cancer Res 78:1017-1030. 10.1158/0008-5472.CAN-17-1318

Dimitriou F, Krattinger R, Ramelyte E, Barysch MJ, Micaletto S, Dummer R, and Goldinger SM. 2018. The World of Melanoma: Epidemiologic, Genetic, and Anatomic Differences of Melanoma Across the Globe. Curr Oncol Rep 20:87. 10.1007/s11912-018-0732-8

Falzone L, Salomone S, and Libra M. 2018. Evolution of Cancer Pharmacological Treatments at the Turn of the Third Millennium. Front Pharmacol 9:1300. 10.3389/fphar.2018.01300

Feng X, Jiang J, Shi S, Xie H, Zhou L, and Zheng S. 2016. Knockdown of miR-25 increases the sensitivity of liver cancer stem cells to TRAIL-induced apoptosis via PTEN/PI3K/Akt/Bad signaling pathway. Int J Oncol 49:2600-2610. 10.3892/ijo.2016.3751

Galasso M, Morrison C, Minotti L, Corra F, Zerbinati C, Agnoletto C, Baldassari F, Fassan M, Bartolazzi A, Vecchione A, Nuovo GJ, Di Leva G, D'Atri S, Alvino E, Previati M, Nickoloff BJ, Croce CM, and Volinia S. 2018. Loss of miR-204 expression is a key event in melanoma. Mol Cancer 17:71. 10.1186/s12943-018-0819-8

Peer) reviewing PDF | (2019:06:38582:1:2:NEW 30 Aug 2019) 
451

452

453

454

455

456

457

458

459

460

461

462

463

464

465

466

467

468

469

470

471

472

473

474

475

476

477

478

479

480

481

482

483

484

485

486

487

488

489

490

491

492

493

494

495

496

497

498

499

500
Grumati P, and Dikic I. 2018. Ubiquitin signaling and autophagy. J Biol Chem 293:5404-5413. 10.1074/jbc.TM117.000117

Gulyaeva LF, and Kushlinskiy NE. 2016. Regulatory mechanisms of microRNA expression. J Transl Med 14:143. 10.1186/s12967-016-0893-X

Guo QJ, Mills JN, Bandurraga SG, Nogueira LM, Mason NJ, Camp ER, Larue AC, Turner DP, and Findlay VJ. 2013. MicroRNA-510 promotes cell and tumor growth by targeting peroxiredoxin1 in breast cancer. Breast Cancer Res 15:R70. 10.1186/bcr3464

Hamidi H, and Ivaska J. 2018. Every step of the way: integrins in cancer progression and metastasis. Nat Rev Cancer 18:533-548. 10.1038/s41568-018-0038-z

Hamzehzadeh L, Atkin SL, Majeed M, Butler AE, and Sahebkar A. 2018. The versatile role of curcumin in cancer prevention and treatment: A focus on PI3K/AKT pathway. $J$ Cell Physiol 233:6530-6537. 10.1002/jcp.26620

Hu H, Li Z, Zhou Y, Zhang Y, Zhao L, Zhao W, Huang Y, and Song X. 2019. GLT8D1 overexpression as a novel prognostic biomarker in human cutaneous melanoma. Melanoma Res. 10.1097/CMR.0000000000000631

Hu Z, Ott PA, and Wu CJ. 2018. Towards personalized, tumour-specific, therapeutic vaccines for cancer. Nat Rev Immunol 18:168-182. 10.1038/nri.2017.131

Huo J, Zhang Y, Li R, Wang Y, Wu J, and Zhang D. 2016. Upregulated MicroRNA-25 Mediates the Migration of Melanoma Cells by Targeting DKK3 through the WNT/beta-Catenin Pathway. Int J Mol Sci 17. 10.3390/ijms17111124

Jamaspishvili T, Berman DM, Ross AE, Scher HI, De Marzo AM, Squire JA, and Lotan TL. 2018. Clinical implications of PTEN loss in prostate cancer. Nat Rev Urol 15:222-234. 10.1038/nrurol.2018.9

Janku F, Yap TA, and Meric-Bernstam F. 2018. Targeting the PI3K pathway in cancer: are we making headway? Nat Rev Clin Oncol 15:273-291. 10.1038/nrclinonc.2018.28

Jayawardana K, Schramm SJ, Tembe V, Mueller S, Thompson JF, Scolyer RA, Mann GJ, and Yang J. 2016. Identification, Review, and Systematic Cross-Validation of microRNA Prognostic Signatures in Metastatic Melanoma. J Invest Dermatol 136:245-254. 10.1038/JID.2015.355

Kapeller J, Houghton LA, Monnikes H, Walstab J, Moller D, Bonisch H, Burwinkel B, Autschbach F, Funke B, Lasitschka F, Gassler N, Fischer C, Whorwell PJ, Atkinson W, Fell C, Buchner KJ, Schmidtmann M, van der Voort I, Wisser AS, Berg T, Rappold G, and Niesler B. 2008. First evidence for an association of a functional variant in the microRNA-510 target site of the serotonin receptor-type 3E gene with diarrhea predominant irritable bowel syndrome. Hum Mol Genet 17:2967-2977. 10.1093/hmg/ddn195

Karimkhani C, Green AC, Nijsten T, Weinstock MA, Dellavalle RP, Naghavi M, and Fitzmaurice C. 2017. The global burden of melanoma: results from the Global Burden of Disease Study 2015. Br J Dermatol 177:134-140. 10.1111/bjd.15510

Kim YK, Yu J, Han TS, Park SY, Namkoong B, Kim DH, Hur K, Yoo MW, Lee HJ, Yang HK, and Kim VN. 2009. Functional links between clustered microRNAs: suppression of cell-cycle inhibitors by microRNA clusters in gastric cancer. Nucleic Acids Res 37:1672-1681. 10.1093/nar/gkp002

Leonardi GC, Falzone L, Salemi R, Zanghi A, Spandidos DA, McCubrey JA, Candido S, and Libra M. 2018. Cutaneous melanoma: From pathogenesis to therapy (Review). Int J Oncol 52:1071-1080. 10.3892/ijo.2018.4287

Levy C, Khaled M, Iliopoulos D, Janas MM, Schubert S, Pinner S, Chen PH, Li S, Fletcher AL, Yokoyama S, Scott KL, Garraway LA, Song JS, Granter SR, Turley SJ, Fisher DE, and Novina CD. 2010. Intronic miR-211 assumes the tumor suppressive function of its host gene in melanoma. Mol Cell 40:841-849. 10.1016/j.molcel.2010.11.020

Peer] reviewing PDF | (2019:06:38582:1:2:NEW 30 Aug 2019) 
501

502

503

504

505

506

507

508

509

510

511

512

513

514

515

516

517

518

519

520

521

522

523

524

525

526

527

528

529

530

531

532

533

534

535

536

537

538

539

540

541

542

543

544

545

546

547

548

549

550

Lin J, Goldstein L, Nesbit A, and Chen MY. 2016. Influence of Hormone Receptor Status on Spinal Metastatic Lesions in Patients with Breast Cancer. World Neurosurg 85:42-48. 10.1016/j.wneu.2015.07.068

Liu R, Chen X, Du Y, Yao W, Shen L, Wang C, Hu Z, Zhuang R, Ning G, Zhang C, Yuan Y, Li Z, Zen $\mathrm{K}, \mathrm{Ba} Y$, and Zhang CY. 2012. Serum microRNA expression profile as a biomarker in the diagnosis and prognosis of pancreatic cancer. Clin Chem 58:610-618. 10.1373/clinchem.2011.172767

Lu Y, Li T, Wei G, Liu L, Chen Q, Xu L, Zhang K, Zeng D, and Liao R. 2016. The long noncoding RNA NEAT1 regulates epithelial to mesenchymal transition and radioresistance in through miR-204/ZEB1 axis in nasopharyngeal carcinoma. Tumour Biol 37:1173311741. 10.1007/s13277-015-4773-4

Luscombe NM, Greenbaum D, and Gerstein M. 2001. What is bioinformatics? A proposed definition and overview of the field. Methods Inf Med 40:346-358.

Mairinger FD, Ting S, Werner R, Walter RF, Hager T, Vollbrecht C, Christoph D, Worm K, Mairinger T, Sheu-Grabellus SY, Theegarten D, Schmid KW, and Wohlschlaeger J. 2014. Different micro-RNA expression profiles distinguish subtypes of neuroendocrine tumors of the lung: results of a profiling study. Mod Pathol 27:1632-1640. 10.1038/modpathol.2014.74

Manzoni C, Kia DA, Vandrovcova J, Hardy J, Wood NW, Lewis PA, and Ferrari R. 2018. Genome, transcriptome and proteome: the rise of omics data and their integration in biomedical sciences. Brief Bioinform 19:286-302. 10.1093/bib/bbw114

Morandi EM, Verstappen R, Zwierzina ME, Geley S, Pierer G, and Ploner C. 2016. ITGAV and ITGA5 diversely regulate proliferation and adipogenic differentiation of human adipose derived stem cells. Sci Rep 6:28889. 10.1038/srep28889

Multhaupt HA, Leitinger B, Gullberg D, and Couchman JR. 2016. Extracellular matrix component signaling in cancer. Adv Drug Deliv Rev 97:28-40. 10.1016/j.addr.2015.10.013

Palmieri G, Colombino M, Casula M, Manca A, Mandala M, Cossu A, and Italian Melanoma I. 2018. Molecular Pathways in Melanomagenesis: What We Learned from NextGeneration Sequencing Approaches. Curr Oncol Rep 20:86. 10.1007/s11912-018-07337

Patnaik SK, Kannisto E, Knudsen S, and Yendamuri S. 2010. Evaluation of microRNA expression profiles that may predict recurrence of localized stage I non-small cell lung cancer after surgical resection. Cancer Res 70:36-45. 10.1158/0008-5472.CAN-09-3153

Peng W, Chen JQ, Liu C, Malu S, Creasy C, Tetzlaff MT, Xu C, McKenzie JA, Zhang C, Liang X, Williams LJ, Deng W, Chen G, Mbofung R, Lazar AJ, Torres-Cabala CA, Cooper ZA, Chen PL, Tieu TN, Spranger S, Yu X, Bernatchez C, Forget MA, Haymaker C, Amaria R, McQuade JL, Glitza IC, Cascone T, Li HS, Kwong LN, Heffernan TP, Hu J, Bassett RL, Jr., Bosenberg MW, Woodman SE, Overwijk WW, Lizee G, Roszik J, Gajewski TF, Wargo JA, Gershenwald JE, Radvanyi L, Davies MA, and Hwu P. 2016. Loss of PTEN Promotes Resistance to T Cell-Mediated Immunotherapy. Cancer Discov 6:202-216. 10.1158/2159-8290.CD-15-0283

Perera E, Gnaneswaran N, Jennens R, and Sinclair R. 2013. Malignant Melanoma. Healthcare (Basel) 2:1-19. 10.3390/healthcare2010001

Piletic K, and Kunej T. 2016. MicroRNA epigenetic signatures in human disease. Arch Toxicol 90:2405-2419. 10.1007/s00204-016-1815-7

Poillet-Perez L, Xie X, Zhan L, Yang Y, Sharp DW, Hu ZS, Su X, Maganti A, Jiang C, Lu W, Zheng H, Bosenberg MW, Mehnert JM, Guo JY, Lattime E, Rabinowitz JD, and White E. 2018. Autophagy maintains tumour growth through circulating arginine. Nature 563:569573. 10.1038/s41586-018-0697-7

Peer) reviewing PDF | (2019:06:38582:1:2:NEW 30 Aug 2019) 
551

552

553

554

555

556

557

558

559

560

561

562

563

564

565

566

567

568

569

570

571

572

573

574

575

576

577

578

579

580

581

582

583

584

585

586

587

588

589

590

591

592

593

594

595

596

597

598

599

600

Richard L. Mort IJJaEEP. 2015. The melanocyte lineage in development and disease. The Company of Biologists Development (2015) 620-632. 10.1242/dev.123729

10.1242/dev.106567

Riefolo M, Porcellini E, Dika E, Broseghini E, and Ferracin M. 2019. Interplay between small and long non-coding RNAs in cutaneous melanoma: a complex jigsaw puzzle with missing pieces. Mol Oncol 13:74-98. 10.1002/1878-0261.12412

Robertson AG, Shih J, Yau C, Gibb EA, Oba J, Mungall KL, Hess JM, Uzunangelov V, Walter V, Danilova L, Lichtenberg TM, Kucherlapati M, Kimes PK, Tang M, Penson A, Babur O, Akbani R, Bristow CA, Hoadley KA, lype L, Chang MT, Network TR, Cherniack AD, Benz C, Mills GB, Verhaak RGW, Griewank KG, Felau I, Zenklusen JC, Gershenwald JE, Schoenfield L, Lazar AJ, Abdel-Rahman MH, Roman-Roman S, Stern MH, Cebulla CM, Williams MD, Jager MJ, Coupland SE, Esmaeli B, Kandoth C, and Woodman SE. 2017. Integrative Analysis Identifies Four Molecular and Clinical Subsets in Uveal Melanoma. Cancer Cell 32:204-220 e215. 10.1016/j.ccell.2017.07.003

Ross CL, Kaushik S, Valdes-Rodriguez R, and Anvekar R. 2018. MicroRNAs in cutaneous melanoma: Role as diagnostic and prognostic biomarkers. J Cell Physiol 233:51335141. 10.1002/jcp.26395

Sanchez-Sendra B, Martinez-Ciarpaglini C, Gonzalez-Munoz JF, Murgui A, Terradez L, and Monteagudo C. 2018. Downregulation of intratumoral expression of miR-205, miR-200c and miR-125b in primary human cutaneous melanomas predicts shorter survival. Sci Rep 8:17076. 10.1038/s41598-018-35317-3

Sarkar D, Leung EY, Baguley BC, Finlay GJ, and Askarian-Amiri ME. 2015. Epigenetic regulation in human melanoma: past and future. Epigenetics 10:103-121. 10.1080/15592294.2014.1003746

Schadendorf D, van Akkooi ACJ, Berking C, Griewank KG, Gutzmer R, Hauschild A, Stang A, Roesch A, and Ugurel S. 2018. Melanoma. The Lancet 392:971-984. 10.1016/s01406736(18)31559-9

Segura MF, Belitskaya-Levy I, Rose AE, Zakrzewski J, Gaziel A, Hanniford D, Darvishian F, Berman RS, Shapiro RL, Pavlick AC, Osman I, and Hernando E. 2010. Melanoma MicroRNA signature predicts post-recurrence survival. Clin Cancer Res 16:1577-1586. 10.1158/1078-0432.CCR-09-2721

Shergalis A, Bankhead A, 3rd, Luesakul U, Muangsin N, and Neamati N. 2018. Current Challenges and Opportunities in Treating Glioblastoma. Pharmacol Rev 70:412-445. 10.1124/pr.117.014944

Wang BD, Ceniccola K, Yang Q, Andrawis R, Patel V, Ji Y, Rhim J, Olender J, Popratiloff A, Latham P, Lai Y, Patierno SR, and Lee NH. 2015. Identification and Functional Validation of Reciprocal microRNA-mRNA Pairings in African American Prostate Cancer Disparities. Clin Cancer Res 21:4970-4984. 10.1158/1078-0432.CCR-14-1566

Wu RY, Kong PF, Xia LP, Huang Y, Li ZL, Tang YY, Chen YH, Li X, Senthilkumar R, Zhang HL, Sun T, Xu XL, Yu Y, Mai J, Peng XD, Yang D, Zhou LH, Feng GK, Deng R, and Zhu XF. 2019. Regorafenib Promotes Antitumor Immunity via Inhibiting PD-L1 and IDO1 Expression in Melanoma. Clin Cancer Res 25:4530-4541. 10.1158/1078-0432.CCR-182840

Xin X, Zhang Y, Ling F, Wang L, Sheng X, Qin L, and Zhao X. 2019. Identification of a ninemiRNA signature for the prognosis of Uveal Melanoma. Exp Eye Res 180:242-249. 10.1016/j.exer.2019.01.004

Yang M, Wan Q, Hu X, Yin H, Hao D, Wu C, and Li J. 2019. Coexpression modules constructed by weighted gene co-expression network analysis indicate ubiquitin-mediated proteolysis as a potential biomarker of uveal melanoma. Exp Ther Med 17:237-243. 10.3892/etm.2018.6945

Peer) reviewing PDF | (2019:06:38582:1:2:NEW 30 Aug 2019) 
601 Yang SX, Polley E, and Lipkowitz S. 2016. New insights on PI3K/AKT pathway alterations and 602 clinical outcomes in breast cancer. Cancer Treat Rev 45:87-96. $603 \quad$ 10.1016/j.ctrv.2016.03.004

604 Zhu C, Ren C, Han J, Ding Y, Du J, Dai N, Dai J, Ma H, Hu Z, Shen H, Xu Y, and Jin G. 2014. A 605 606 607 608 five-microRNA panel in plasma was identified as potential biomarker for early detection of gastric cancer. Br J Cancer 110:2291-2299. 10.1038/bjc.2014.119

Zoni E, van der Horst G, van de Merbel AF, Chen L, Rane JK, Pelger RC, Collins AT, Visakorpi T, Snaar-Jagalska BE, Maitland NJ, and van der Pluijm G. 2015. miR-25 Modulates Invasiveness and Dissemination of Human Prostate Cancer Cells via Regulation of

612 alphav- and alpha6-Integrin Expression. Cancer Res 75:2326-2336. 10.1158/00085472. CAN-14-2155 


\section{Figure 1}

Volcano maps

DEMs in GSE35579 between melanoma and nevi: green represents down regulation in melanoma $(\log \mathrm{FC}<-1)$; red represents up regulation in melanoma $(\log \mathrm{FC}>1) ; \mathrm{P}<0.05$. 


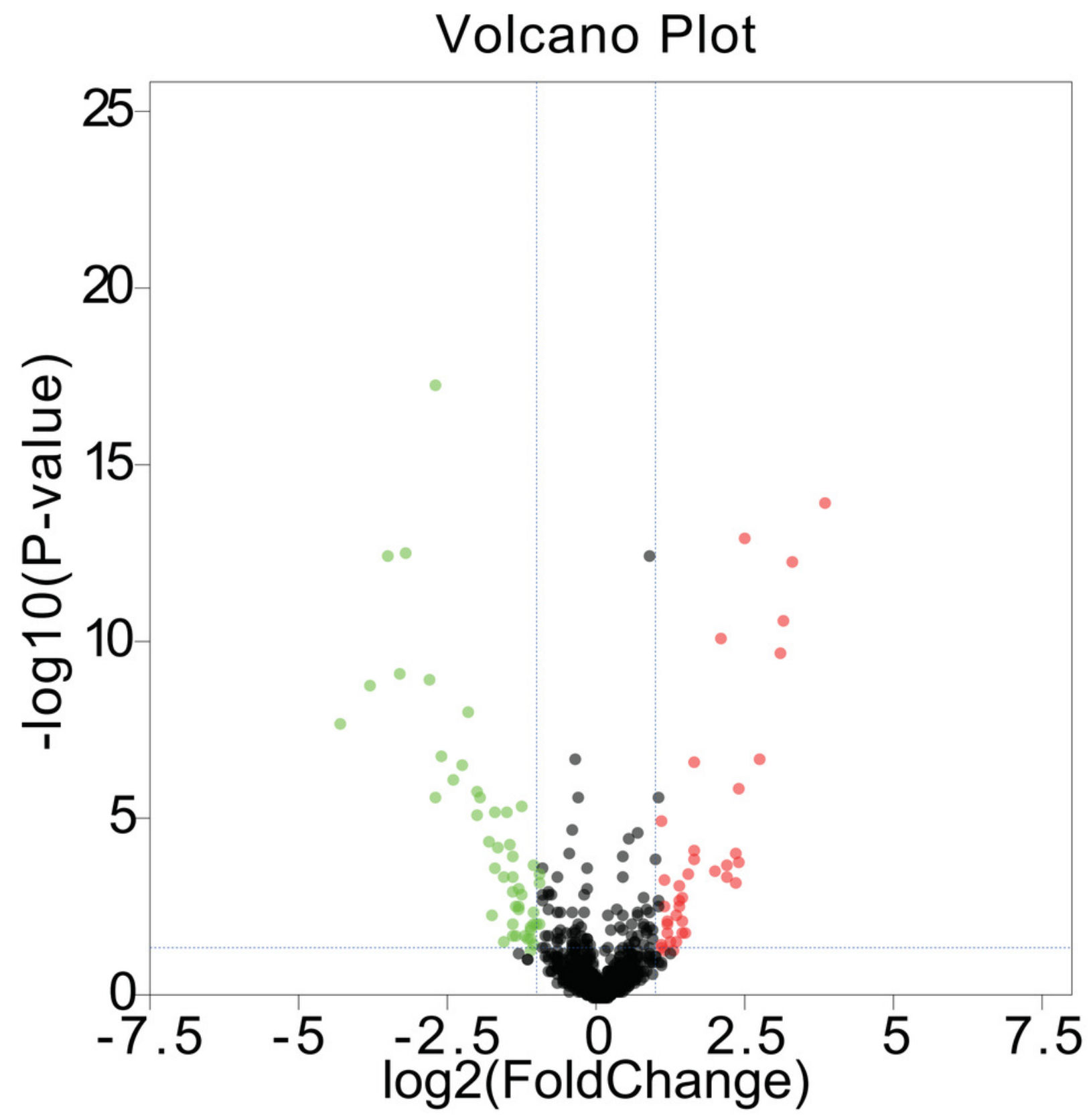


Figure 2

\section{A hierarchic figure}

Hierarchic analysis: green, black and red indicate the top 100 downregulated, nonsignificantly differentially expressed and up regulated DEMs, Respectively 


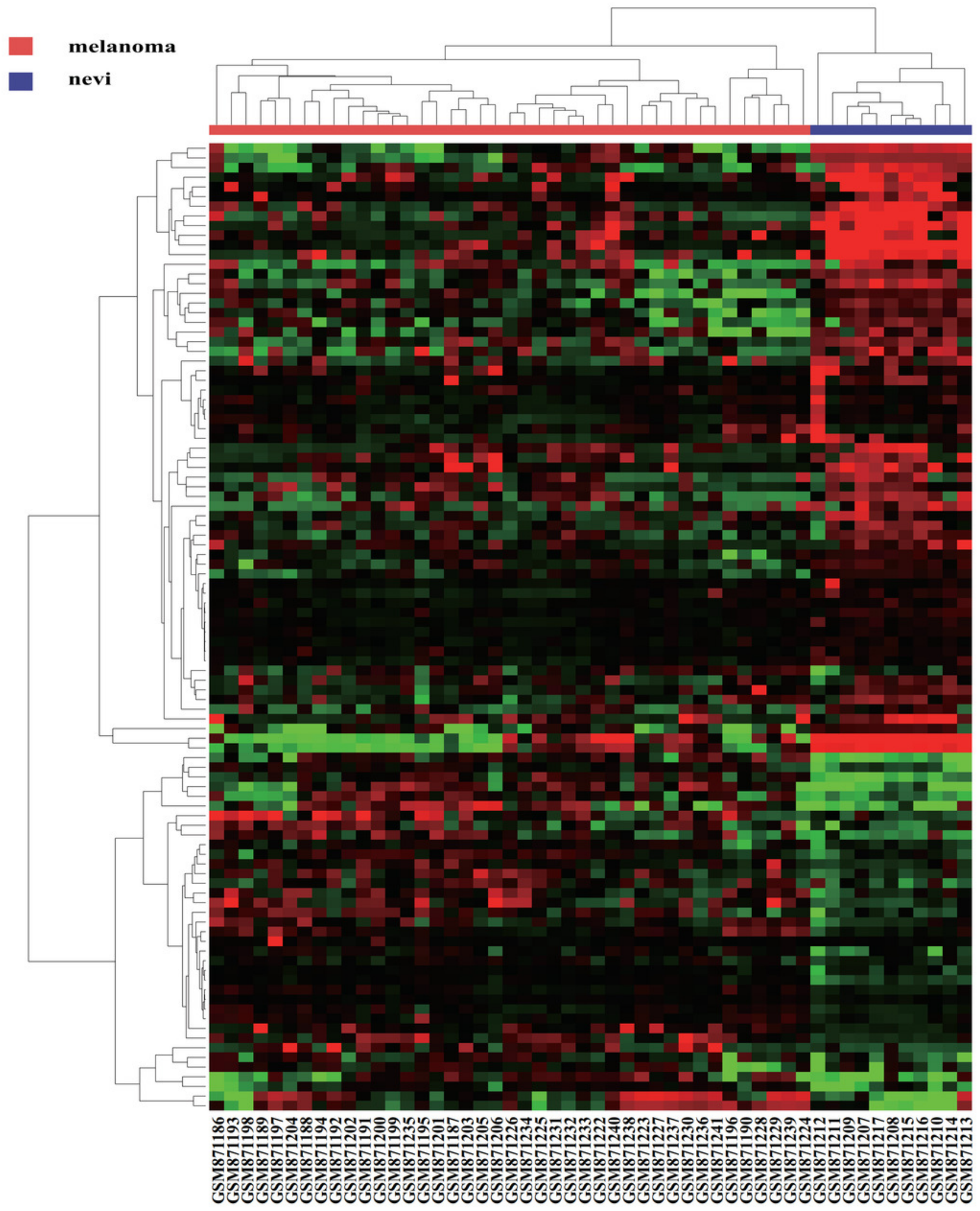




\section{Figure 3}

survival analysis and prognosis of cutaneous melanoma patients from TCGA.

Fig.3A-3E show that the prognostic characteristics of these five miRNAs(miR-25,miR-204,miR-211,miR-510,miR-513c); Fig.3F show that the prognostic characteristics of a 5-miRNA signature (miR-25,miR-204,miR-211,miR-510,miR-513c). Blue curves represent the low expression group, and red curves represent the high expression group 
A

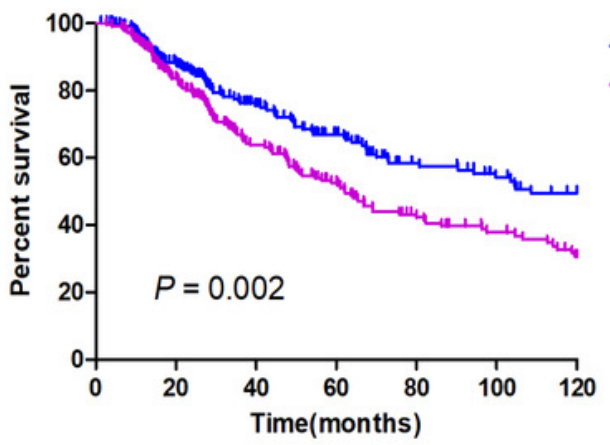

C

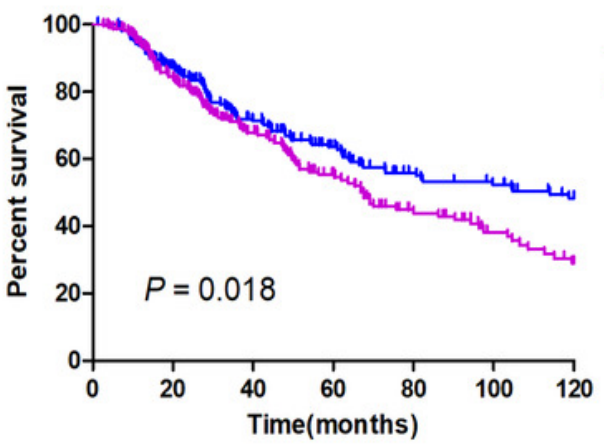

E

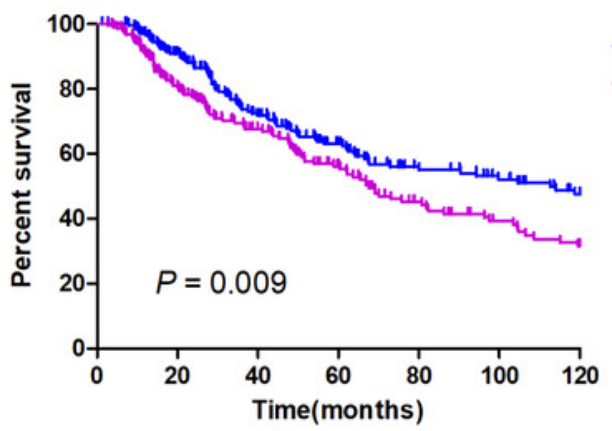

B

miR-204

$\perp$ low-expression

$\perp$ high-expression

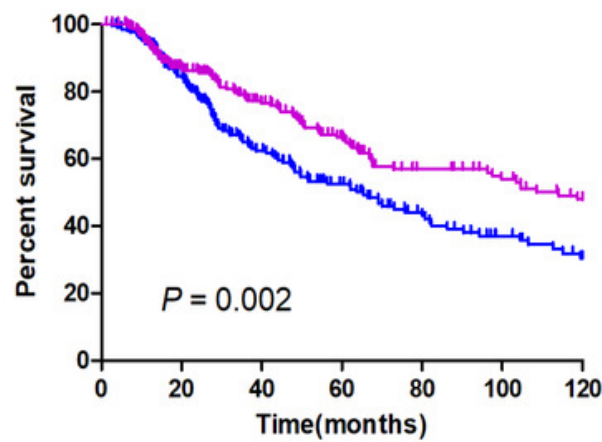

- low-expression

$\perp$ high-expression

D

$\operatorname{miR}-510$

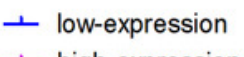

$\perp$ high-expression

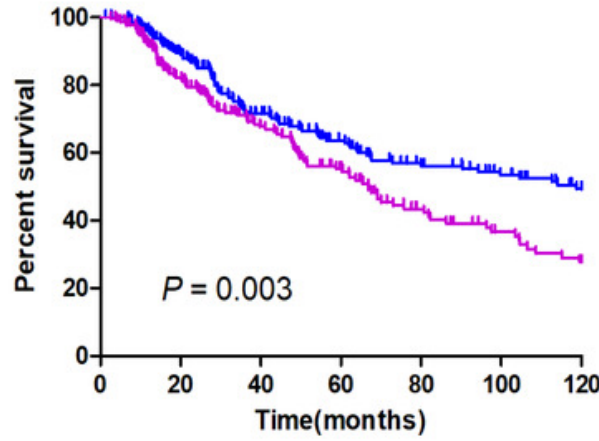

- low-expression

$\perp$ high-expression

F

- low-expression

+ high-expression

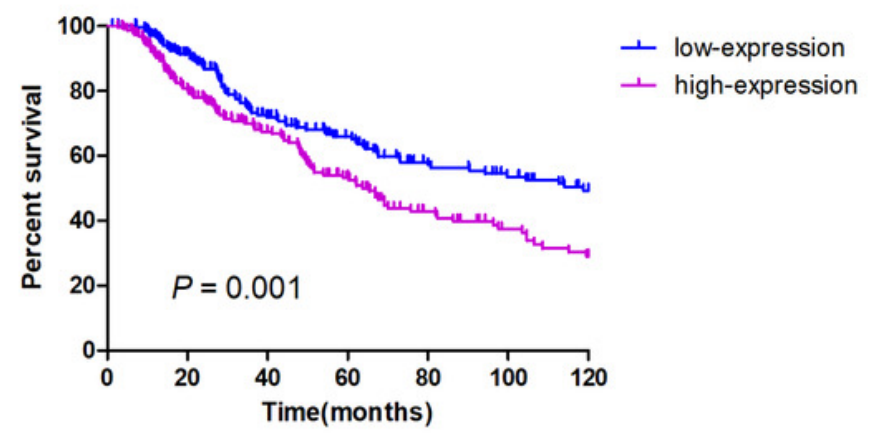


Figure 4

Venn diagrams

Target genes of the five DEMs were identified by four software programs, including TargetScan, miRDB, DIANA and miRmap, to acquire overlapping genes by Funrich tool. 

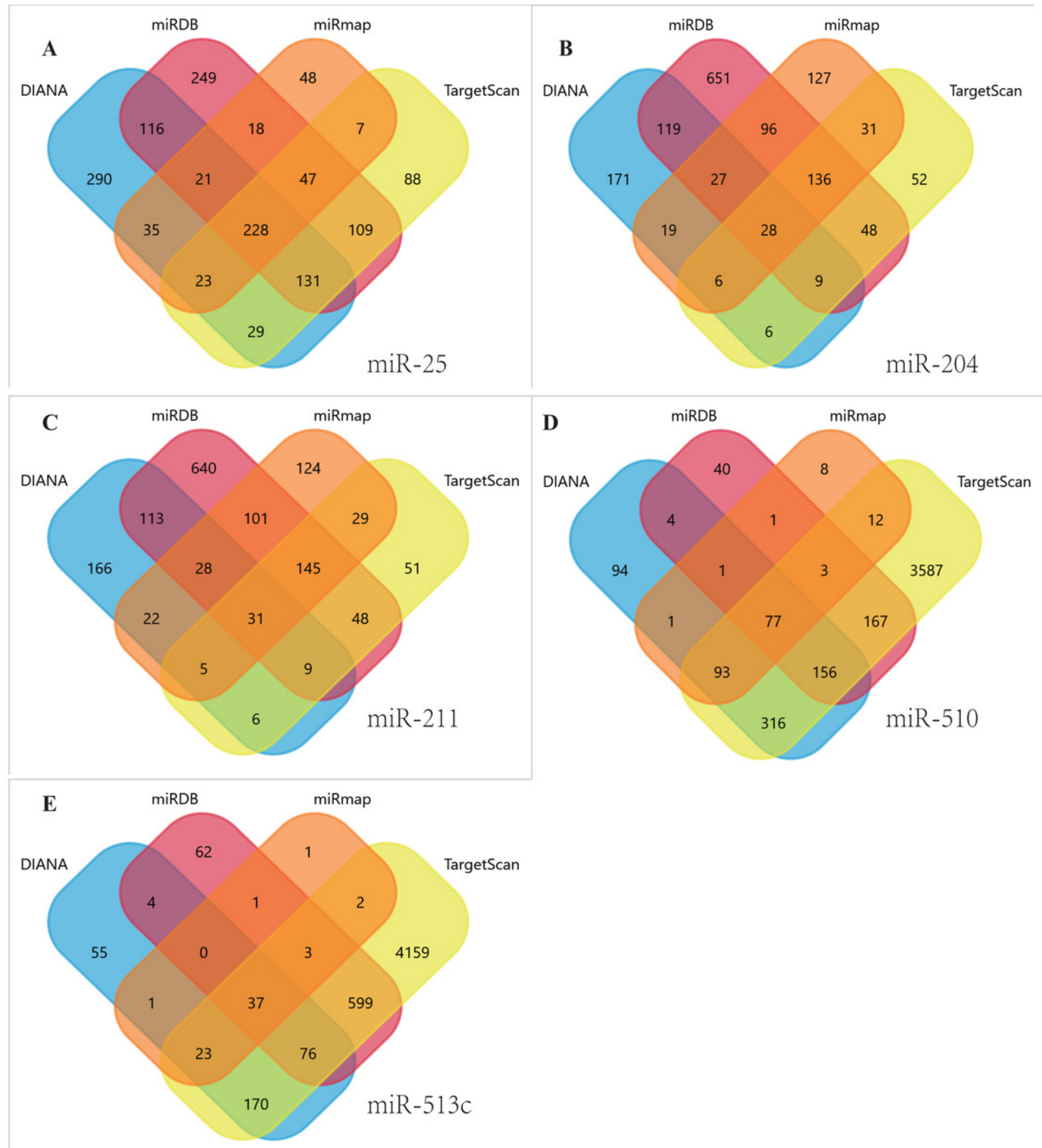
Figure 5

GO and KEGG pathway analyses

(A) The biological process (BP) analysis; (B) Cellular component (CC) analysis; (C) Molecular function (MF) analysis; (D) KEGG pathway analysis. 
A

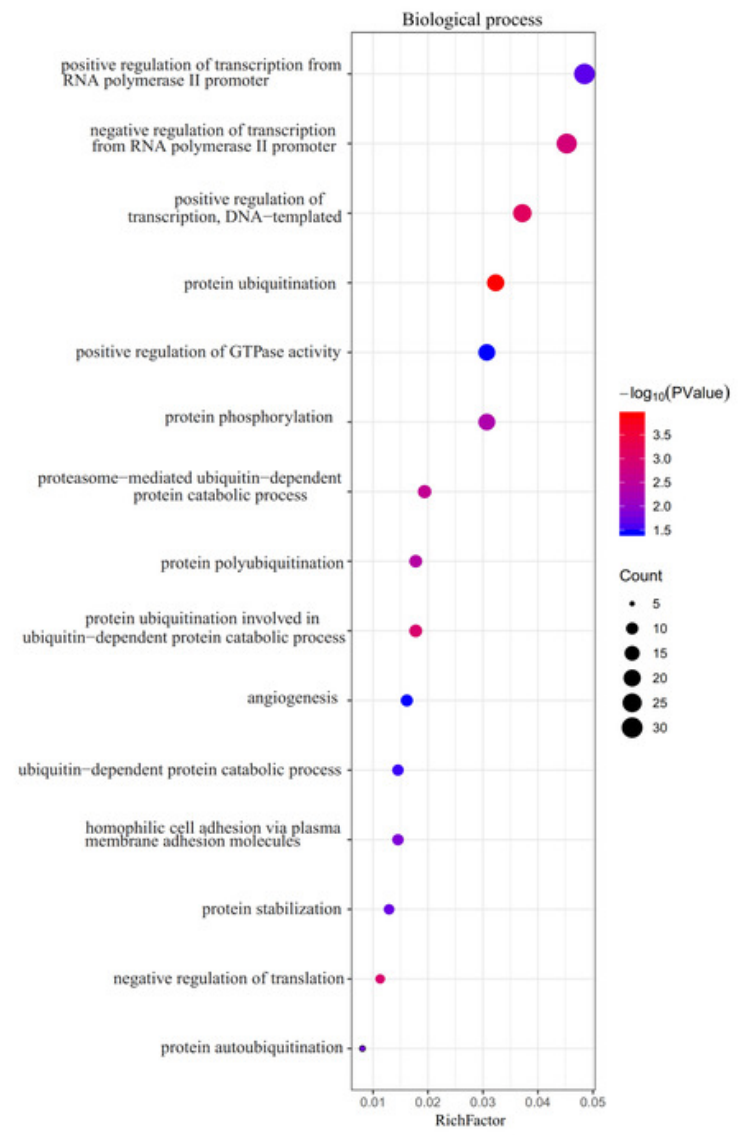

C

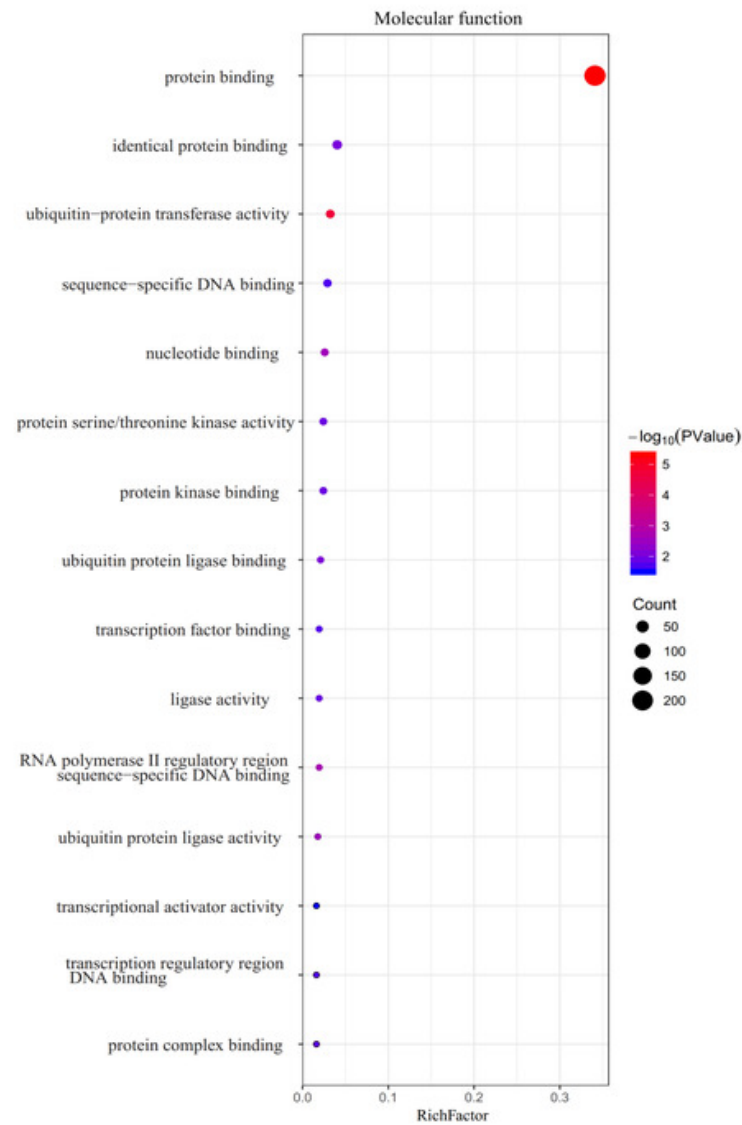

B
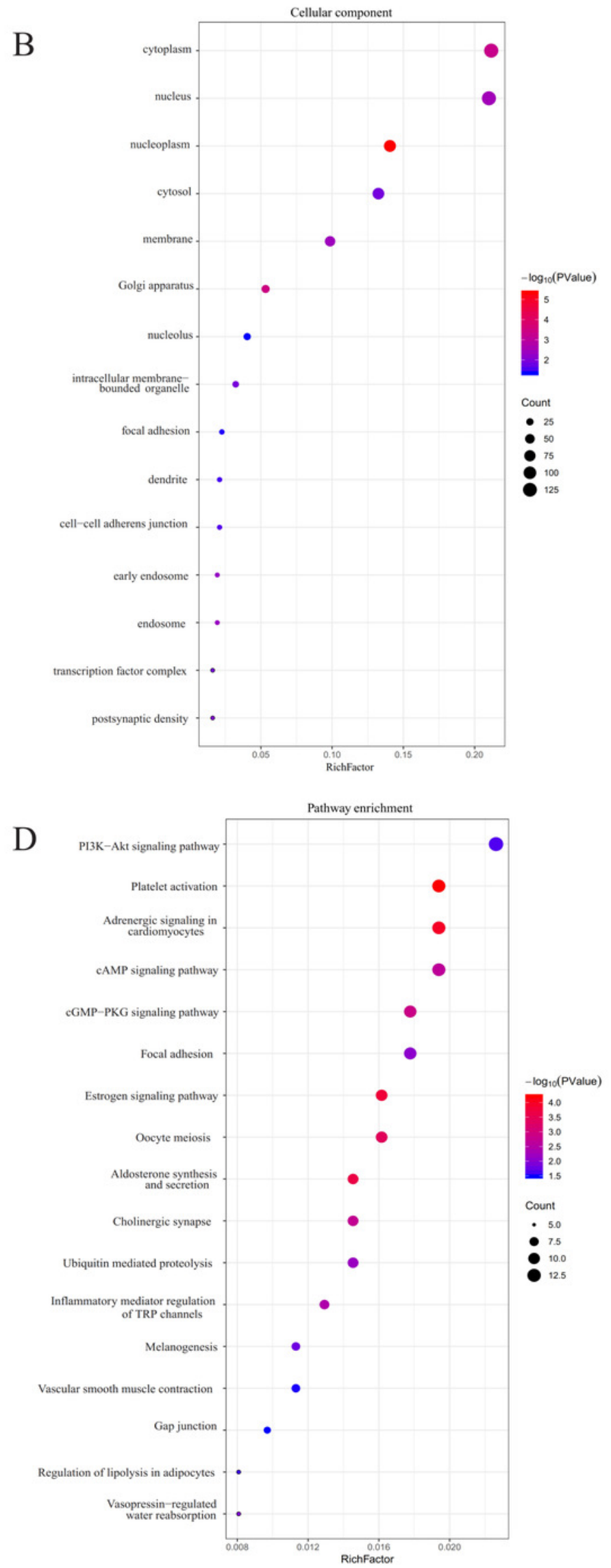


\section{Table $\mathbf{1}$ (on next page)}

Clinicalfeature of melanoma patients from TCGA 
Table 1 Clinical feature of melanoma patients from TCGA

\begin{tabular}{|c|c|}
\hline Variables & Case,n(\%) \\
\hline \multicolumn{2}{|c|}{ Age at diagnosis(yr) } \\
\hline$<60$ & 241 \\
\hline$\geq 60$ & 221 \\
\hline NA & 8 \\
\hline \multicolumn{2}{|l|}{ Gender } \\
\hline Male & 290 \\
\hline Female & 180 \\
\hline \multicolumn{2}{|l|}{ T stage } \\
\hline $\mathrm{T} 0$ & 23 \\
\hline $\mathrm{T} 1(\mathrm{a}+\mathrm{b})$ & 42 \\
\hline $\mathrm{T} 2(\mathrm{a}+\mathrm{b})$ & 78 \\
\hline $\mathrm{T} 3(\mathrm{a}+\mathrm{b})$ & 90 \\
\hline $\mathrm{T} 4(\mathrm{a}+\mathrm{b})$ & 143 \\
\hline Tis & 8 \\
\hline TX & 47 \\
\hline NA & 29 \\
\hline \multicolumn{2}{|c|}{ Pathologic stage } \\
\hline Stage 0 & 7 \\
\hline Stage I & 77 \\
\hline Stage II & 140 \\
\hline I/II NOS & 14 \\
\hline Stage III & 171 \\
\hline Stage IV & 23 \\
\hline NA & 38 \\
\hline \multicolumn{2}{|l|}{ Node status } \\
\hline No & 235 \\
\hline N1-3 & 178 \\
\hline $\mathrm{Nx}$ & 36 \\
\hline NA & 21 \\
\hline \multicolumn{2}{|l|}{ Metastasis } \\
\hline M0 & 418 \\
\hline M1 & 24 \\
\hline NA & 28 \\
\hline
\end{tabular}

1 NA:Not available 


\section{Table 2 (on next page)}

The prognosticrelated differentially expressed miRNAs identifed between melanoma and nevi 
1 Table 2 The prognostic related differentially expressed miRNAs identifed between melanoma and nevi

\begin{tabular}{llll}
\hline Down-regulation DEMs & P-value & up-regulation & P-value \\
\hline hsa-miR-211 & 0.033 & hsa-miR-25 & 0.004 \\
hsa-miR-204 & 0.001 & & \\
hsa-miR-510 & 0.007 & & \\
hsa-miR-513c & 0.014 & & \\
\hline
\end{tabular}

2 DEMs: Differentially expressed miRNAs

3 


\section{Table 3(on next page)}

Associationbetween the five miRNAs and melanoma cancer clinical characters 
1 Table 3 Association between the five miRNAs and melanoma cancer clinical characters

2

\begin{tabular}{|c|c|c|c|c|c|c|c|c|c|c|c|c|c|c|c|}
\hline \multirow[t]{3}{*}{ Variables } & \multirow{2}{*}{\multicolumn{2}{|c|}{$\begin{array}{r}\text { miR-25 } \\
\text { expression }\end{array}$}} & \multirow[b]{3}{*}{$P$} & \multirow{2}{*}{\multicolumn{2}{|c|}{$\begin{array}{l}\text { miR-204 } \\
\text { expression }\end{array}$}} & \multirow[b]{3}{*}{$P$} & \multirow{2}{*}{\multicolumn{2}{|c|}{$\begin{array}{l}\text { miR-211 } \\
\text { expression }\end{array}$}} & \multirow[b]{3}{*}{$P$} & \multirow{2}{*}{\multicolumn{2}{|c|}{$\begin{array}{l}\text { miR-510 } \\
\text { expression }\end{array}$}} & \multirow[b]{3}{*}{$P$} & \multirow{2}{*}{\multicolumn{2}{|c|}{$\begin{array}{l}\text { miR-513c } \\
\text { expression }\end{array}$}} & \multirow[b]{3}{*}{$P$} \\
\hline & & & & & & & & & & & & & & & \\
\hline & low & high & & low & high & & low & high & & low & high & & low & high & \\
\hline \multicolumn{16}{|l|}{ Age } \\
\hline$<\mathbf{6 0}$ & 124 & 106 & 0.064 & 92 & 138 & $<0.000 *$ & 122 & 108 & 0.175 & 119 & 111 & 0.379 & 115 & 115 & 0.755 \\
\hline$\geq 60$ & 89 & 109 & & 118 & 80 & & 92 & 106 & & 94 & 104 & & 96 & 102 & \\
\hline \multicolumn{16}{|l|}{ gender } \\
\hline Female & 80 & 81 & 0.980 & 83 & 78 & 0.424 & 73 & 88 & 0.134 & 76 & 85 & 0.411 & 73 & 88 & 0.203 \\
\hline Male & 133 & 134 & & 127 & 140 & & 141 & 126 & & 137 & 130 & & 138 & 129 & \\
\hline \multicolumn{16}{|l|}{ T stage } \\
\hline $\mathrm{T} 1+\mathrm{T} 2$ & 75 & 62 & 0.157 & 54 & 83 & $0.004 *$ & 84 & 53 & $<0.000^{*}$ & 79 & 58 & $0.003 *$ & 75 & 62 & 0.037 * \\
\hline T3+T4 & 103 & 116 & & 121 & 98 & & 89 & 130 & & 91 & 128 & & 95 & 124 & \\
\hline \multicolumn{16}{|c|}{ Lymph node } \\
\hline status & & & & & & & & & & & & & & & \\
\hline No & 106 & 108 & 0.758 & 107 & 107 & 0.955 & 107 & 107 & 0.955 & 109 & 105 & 0.811 & 103 & 111 & 0.516 \\
\hline N1-2 & 82 & 89 & & 86 & 85 & & 85 & 86 & & 85 & 86 & & 88 & 83 & \\
\hline \multicolumn{16}{|l|}{ Mestasis } \\
\hline M0 & 192 & 193 & 0.841 & 189 & 196 & 0.769 & 188 & 197 & 0.243 & 193 & 192 & 0.823 & 188 & 197 & 0.458 \\
\hline M1 & 10 & 11 & & 11 & 10 & & 13 & 8 & & 10 & 11 & & 12 & 9 & \\
\hline \multicolumn{16}{|c|}{ Clinical stage } \\
\hline I + II & 107 & 95 & 0.166 & 102 & 100 & 0.715 & 97 & 105 & 0.512 & 97 & 105 & 0.738 & 93 & 109 & 0.250 \\
\hline III+IV & 84 & 99 & & 89 & 94 & & 94 & 89 & & 91 & 92 & & 95 & 88 & \\
\hline \multicolumn{16}{|l|}{ Breslow } \\
\hline \multicolumn{16}{|l|}{ depth } \\
\hline \multicolumn{16}{|l|}{ value(mm) } \\
\hline$<3$ & 83 & 77 & 0.255 & 70 & 90 & $0.041^{*}$ & 91 & 69 & $<0.000 *$ & 91 & 69 & $<0.000 *$ & 84 & 76 & $0.015^{*}$ \\
\hline$\geq 3$ & 78 & 93 & & 94 & 77 & & 61 & 110 & & 61 & 110 & & 67 & 104 & \\
\hline
\end{tabular}

3

$4 \quad * \boldsymbol{P}<\mathbf{0 . 0 5}$ was considered statistically significant 


\section{Table 4 (on next page)}

TCGA univariable and multivariable Cox regression analysis 
1 Table 4 TCGA univariable and multivariable Cox regression analysis

2

3 3 4

\begin{tabular}{|c|c|c|c|c|c|}
\hline \multirow[t]{2}{*}{ Variables } & \multicolumn{2}{|l|}{ Univariate analysis } & \multicolumn{2}{|l|}{ Multivariate analysis } & \multirow{3}{*}{$\begin{array}{l}\text { was } \\
\text { consider } \\
\text { ed } \\
\text { statistica }\end{array}$} \\
\hline & $\operatorname{HR}(95 \% \mathrm{CI})$ & $P$ value & $\operatorname{HR}(95 \% \mathrm{CI})$ & $P$ value & \\
\hline $\begin{array}{l}\text { age at diagnosis } \\
(\geq 60 \text { vs. }<60)\end{array}$ & $1.563(1.166-2.096)$ & $0.003 *$ & $1.199(0.839-1.714)$ & 0.319 & \\
\hline $\begin{array}{l}\text { T stage } \\
\qquad(\mathrm{T} 3+\mathrm{T} 4 \text { vs. } \mathrm{T} 1+\mathrm{T} 2)\end{array}$ & $0.443(0.316-0.622)$ & $<0.000^{*}$ & $0.825(0.468-1.456)$ & 0.507 & $\begin{array}{l}\text { lly } \\
\text { significa }\end{array}$ \\
\hline $\begin{array}{l}\text { N stage } \\
\qquad \text { (N1-2 vs. N0) }\end{array}$ & $0.517(0.380-0.703)$ & $<0.000^{*}$ & $0.246(0.087-0.699)$ & $0.008^{*}$ & $\mathrm{nt}$ \\
\hline $\begin{array}{l}\text { M stage } \\
\text { (M1 vs. M0) }\end{array}$ & $0.554(0.292-1.051)$ & 0.071 & $0.616(0.218-1.741)$ & 0.361 & \\
\hline $\begin{array}{l}\text { Clinical stage } \\
\qquad(\mathrm{III}+\mathrm{IV} \text { vs. I + II })\end{array}$ & $0.543(0.399-0.738)$ & $<0.000^{*}$ & $1.986(0.691-5.708)$ & 0.203 & \\
\hline $\begin{array}{l}\text { Gender } \\
\text { (Male vs. Female) }\end{array}$ & $0.997(0.734-1.355)$ & 0.986 & $1.040(0.726-1.491)$ & 0.830 & \\
\hline $\begin{array}{l}\text { Breslow depth value } \\
\text { ( } \geq 3 \mathrm{~mm} \text { vs. }<3 \mathrm{~mm} \text { ) }\end{array}$ & $0.370(0.265-0.518)$ & $<0.000^{*}$ & $0.509(0.302-0.859)$ & $0.011 *$ & \\
\hline $\begin{array}{l}\text { Five-miRNA signature } \\
\text { (high risk vs. low risk) }\end{array}$ & $0.613(0.456-0.823)$ & $0.001 *$ & $0.605(0.424-0.863)$ & $0.006^{*}$ & \\
\hline
\end{tabular}

